in this book, as that topic constitutes the subject of the second volume. The author, in the preface, refers to the fact that it has not been possible to recast the many numerical problems on the basis of post-war costs. This is surely an omission for which little apology is needed in these days.

When the first edition of this book was produced more than twenty years ago, the recognition of the importance to all engineers of an elementary knowledge of basic economics applied to their special fields was by no means universal as it is to-day. For the electrical engineer Mr. Bolton's book rendered fundamental economic considerations readily intelligible through the medium of familiar problems. Despite the price changes which have made so many of the examples no longer representative and the much more far-reaching changes which have taken place in the general economic structure, Mr. Bolton's book remains an excellent introductory treatise useful both to the student and to the practising engineer.

JAMES GREIG

\section{DESIGN AND FITTING OF LABORATORIES}

\section{Laboratory Design}

National Research Council Report on Design, Construction and Equipment of Laboratories. Edited by H. S. Coleman. Pp. ix +393 . (New York: Reinhold Publishing Corporation; London: Chap. man and Hall, Ltd., 1951.) 96s. net.

$\mathrm{H}^{\mathrm{P}}$

ROM time to time the scientific professions bestir themselves, sit back from their microscopes and balances, and cast a jaundiced eye around their work-places, the offices and laboratories, lecture theatres and test-shops in which they pass their lives. So many of these places are inadequate in so many ways that dissatisfaction wells up and erupts in meetings and symposia of the kind organized a year or so ago by the Institute of Physics at the Royal Institution. This gathering of distinguished people discussed at considerable length the problems which remain conspicuously unsolved in the design of physics laboratories. More recently a meeting of the Royal Institute of Chemistry considered the shortcomings of chemistry laboratories, and revealed a great many. Neither discussion has had any significant influence on designers because very few designers were invited to hear the scientific workers' views, and none was asked to present his own. Here is an odd state of things. It is as though one might complain of an ill-fitting suit, but not allow the tailor to get near enough to take one's measurements.

American men of science, if not yet actually anxious to be measured, at least recognize the need; and Mr. H. S. Coleman, who, as chairman of the National Research Council's Committee on Design, Construction and Equipment of Laboratories, has edited this imposing volume of essays, has been careful not to exclude contributions from architects, though they amount to only four in a total of forty-two. One of the four is, however, the introduction, by Mr. Roland Wank, a member of the architectural firm of Fellheimer and Wagner, of New York, and he makes good use of so prominent an opportunity to emphasize the vital importance of the architect's role in any building project. He points out that ". . . the architect pre-occupied with appearance and devoted to strait-jacketing functional requirements into a Gothic or Renaissance shell has become rare to the point of extinction ..." and claims with every justification that the architect-authors of other papers in the book reveal their "grasp of the whole range of problems from site selection to the last shut-off valve". It is therefore disappointing to find, on turning to the section devoted to descriptions of modern laboratories, that, with two marked exceptions, the architectural character smacks unpleasantly of the Great West Road out of London, and in at least one case the spacing of the windows in the more recent additions is stated to be controlled by the 1929 "classic" proportions of the original building. (The "classic cornice and detail" are, however, omitted.)

If this means that examples of good contemporary laboratory design are as hard to find in the United States as they are in Great Britain, the lack of a comprehensive reference work of this sort may well have been at least part of the cause. It will no longer be an excuse, for in one way or another-and frequently more than once-every aspect of the subject is here touched upon. The material is arranged in four parts. Part 1 has, as well as the introduction, six essays by specialists in the various fields of services, plumbing, furniture, safety precautions and, most important, materials suitable for use in the interior construction of laboratories. Parts 2 and 3 deal respectively with the requirements of teaching and industrial laboratories, and Part 4 consists of "concise" descriptions of finished laboratories. It is mainly in this part that references to research laboratories are to be found. The editor's declared policy has been to allow each contributor to express his views freely, and there has been no attempt to "conciliate conflicting opinion or eliminate... repetition". The result is that the book is almost too lavish. There is so much reading matter in it (little of it 'concise' as the word is understood in paper-starved Britain) that one is almost handicapped when seeking specific information by the temptation to 'browse' in interesting and enthusiastically presented matters which may not be one's immediate concern.

This is not to deny the book's immense value, of which there can be no doubt whatever. But if another edition is contemplated, would it be too much to ask that one section at least should present the basic information in some sort of classified or tabulated form for quick reference? This would help both the scientific worker and the architect-the one in the formulation of his 'brief', the quality of which has a much more important influence on the success of the finished building than is generally appreciated, and the other in his complex task of seeing the job whole without losing sight of the detail.

The book is handsomely produced on art paper. The text is set in 10-point Rockwell (attractive to look at but a little tiresome to read) with headings and sub-headings in heavy Gill sans, type faces which compose well with the frequently occurring photo. graphs and line drawings. The illustrations are not as good as they should be in such a volume; they illustrate well enough, but they scarcely ever grace the pages, and in some cases-p. 165, for examplethey are disastrously large and black and ugly. Neat little free-hand sketches at one-third the size would have been quite adequate for most of the essays. A book on design should set the best possible example.
S. MEYRICK 